\title{
Inhibition of mouse liver respiration by Chelidonium majus isoquinoline alkaloids
}

\author{
M. Carmo Barreto ${ }^{a, *}$, Ruy E. Pinto ${ }^{\text {b,c }}$, João D. Arrabaça ${ }^{\text {d, }}$ \\ M. Leonor Pavão ${ }^{a}$ \\ a Departamento de Ciências Tecnológicas e Desenvolvimento, Centro de Investigação de Recursos Naturais, \\ Universidade dos Açores, Rua da Mãe de Deus, 9502 Ponta Delgada, Portugal \\ ${ }^{\mathrm{b}}$ Grupo de Bioquímica e Biologia Teóricas, Instituto Bento da Rocha Cabral, 1250-047 Lisbon, Portugal \\ c Departamento de Química e Bioquímica, Centro de Estudos de Bioquímica e Fisiologia, Faculdade de Ciências da \\ Universidade de Lisboa, Campo Grande 1749-016, Lisbon, Portugal \\ ${ }^{\mathrm{d}}$ Departamento de Biologia Vegetal, Centro de Engenharia Biológica, Faculdade de Ciências da Universidade de Lisboa, \\ Campo Grande 1749-016, Lisbon, Portugal
}

Received 17 December 2002; received in revised form 18 August 2003; accepted 1 September 2003

\section{Abstract}

The alkaloids from Chelidonium majus L. which had a significant inhibitory effect in mitochondrial respiration were those which contain a positive charge due to a quaternary nitrogen atom, i.e., chelerythrine, sanguinarine, berberine and coptisine, both with malate + glutamate or with succinate as substrates. When malate + glutamate was used as substrate, chelerythrine and berberine, which contain methoxy groups, were particularly more active, since they had a strong effect even at low concentrations. In submitochondrial particles, berberine and coptisine had a marked inhibitory effect on NADH dehydrogenase activity but practically no effect on succinate dehydrogenase activity, whereas chelerythrine and sanguinarine inhibited more strongly succinate dehydrogenase than NADH dehydrogenase, which is in agreement with the results found for mitochondrial respiration. Protopine and allocryptopine, which did not inhibit mitochondrial respiration, strongly inhibited NADH dehydrogenase in submitochondrial particles, but had no effect on succinate dehydrogenase activity.

(C) 2003 Published by Elsevier Ireland Ltd.

Keywords: Protoberberine alkaloids; Benzophenanthridine alkaloids; Structure-activity relationship; Mitochondrial respiration; NADH dehydrogenase; Succinate dehydrogenase

\section{Introduction}

Chelidonium majus L. is a plant which grows in the wild in Southern and Central Europe, part of Asia,

\footnotetext{
* Corresponding author. Tel.: +351-2966-50183; fax: $+351-2966-50171$.

E-mail address: barreto@notes.uac.pt (M.C. Barreto).
}

North America and in the Azores archipelago (Kadan et al., 1990; Pavão and Pinto, 1995; Colombo and Bosisio, 1996). Its use as a medicinal plant is very ancient (Paris and Moyse, 1967; Duke, 1985; Xème Pharmacopée Française, 1989; Bézanger-Beauquesne et al., 1990). The medicinal properties mentioned above can be ascribed to the more than 27 alkaloids present in the root and aerial part of the plant, which

1 0378-4274/\$ - see front matter @ 2003 Published by Elsevier Ireland Ltd.

2 doi:10.1016/j.toxlet.2003.09.007 

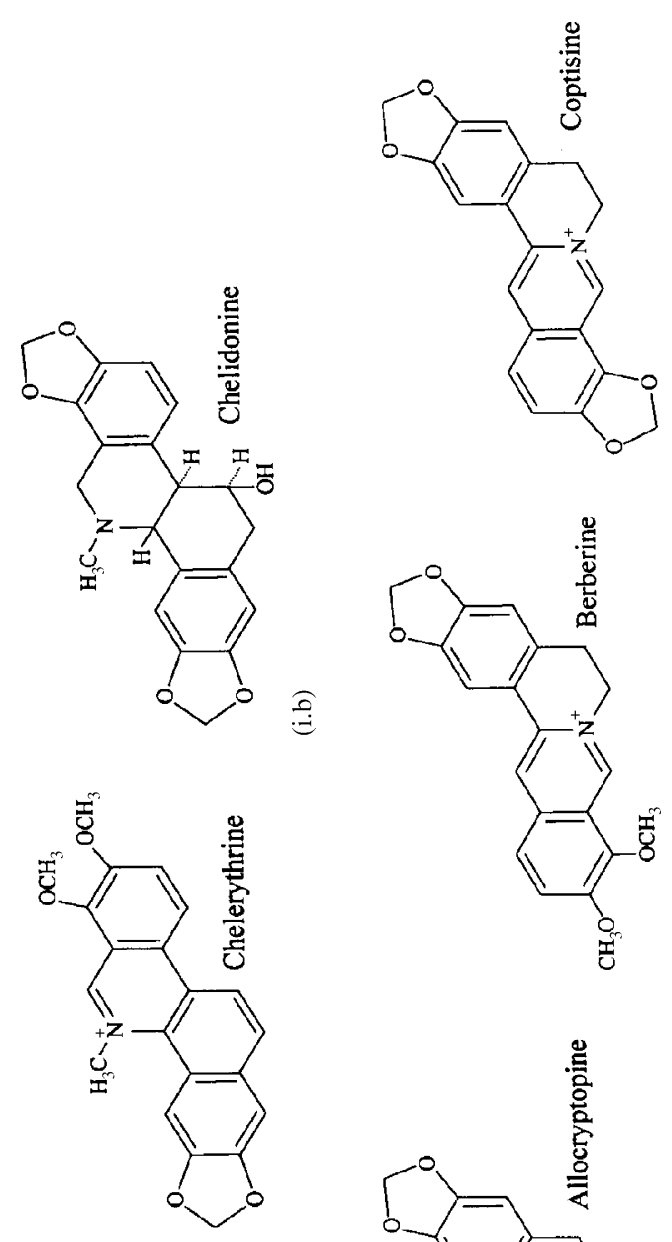

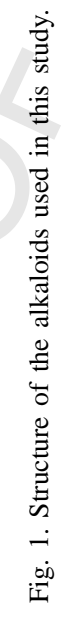
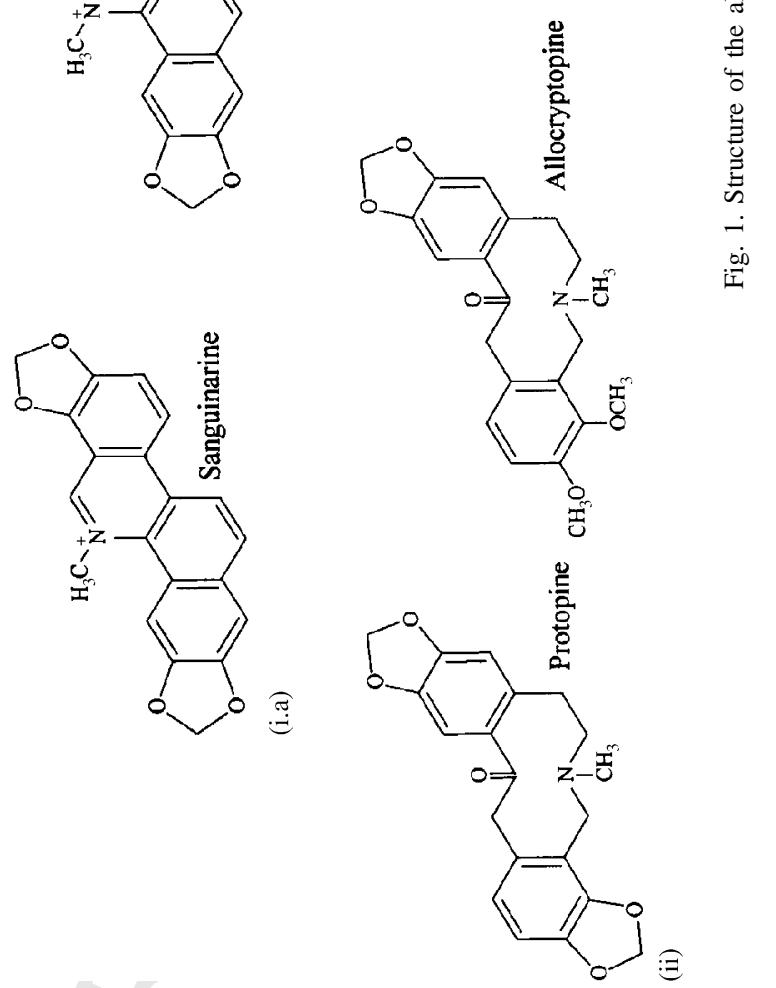
belong to three main groups (Fig. 1): (i) benzo[c]phenanthridines, with two subgroups, (i.a) quaternary, like chelerythrine and sanguinarine or (i.b) tertiary, like chelidonine, (ii) protopine and derived thereof, such as protopine and allocryptopine, and (iii) protoberberines such as berberine and coptisine (Lavenir and Paris, 1965; Táborská et al., 1994; Pavão and Pinto, 1995; Tomé and Colombo, 1995; Colombo and Bosisio, 1996). The interest of this plant for medicinal purposes implies the need to know as much as possible about the effects on metabolic processes of the alkaloids it contains. Several alkaloids with the same or related structures have been found to interfere with respiration, either at the level of the electron transport chain (Schewe and Müller, 1976) or as uncouplers (Vallejos and Rizzotto, 1972). Since mitochondrial respiration is the core of metabolic energy, and therefore a process with major importance, in the present work we investigated the effect of some of these alkaloids (Fig. 1) in respirationlinked processes. We selected alkaloids from each of the main groups found in the plants collected in S. Miguel Island, Azores (Pavão and Pinto, 1995). The effects of phenanthrene were also monitored, to allow for effects due only to the aromatic structure of the molecules.

The aim of the present work is (a) to ascertain whether the effects detected follow a similar pattern within each group; (b) if any effect which occurs on oxygen uptake can be explained by events at the level of NADH dehydrogenase (NADH:ubiquinone oxidoreductase, EC 1.6.99.3) or succinate dehydrogenase (succinate:ubiquinone oxidoreductase, EC 1.3.99.1). These two complexes were chosen by their crucial role in the respiratory chain and by evidence from other authors that these systems might be affected by compounds of this type (Schewe and Müller, 1976; McNaught et al., 1995, 1996).

\section{Materials and methods}

\subsection{Animals}

The animals used were male albino mice, with approximately 12 weeks of age and an average weight of $20-25 \mathrm{~g}$. The animals were fed ad libitum with a commercial chow and tap water.

\subsection{Alkaloids}

Chelidonine, berberine chloride and sanguinarine chloride were purchased from Sigma. The other alkaloids were a kind gift from Prof. Slavik (Masaryk University, Brno, Czech Republic). The alkaloids and phenanthrene were used in methanolic solutions. The effect of methanol was tested for all types of experiment, in the range of volumes added to the assay media, and found to be negligible.

\subsection{Preparation of mitochondria and submitochondrial particles}

Liver mitochondria and submitochondrial particles were isolated according to a published method (Cain and Skilleter, 1987). Protein concentrations were determined using the Bradford Coomassie G250 dye procedure (Bradford, 1976) with bovine serum albumin as standard.

\subsection{Oxygen uptake by mitochondria}

Oxygen uptake was monitored in a Hansatech Clark-type electrode, model DW1 with a CB1 control box. Oxygen uptake by intact mitochondria was monitored at $30^{\circ} \mathrm{C}$ in the presence of either $10 \mathrm{mM}$ malate plus $10 \mathrm{mM}$ glutamate or of $10 \mathrm{mM}$ succinate. The assay medium was $250 \mathrm{mM}$ sucrose, $10 \mathrm{mM}$ Tris- $\mathrm{HCl} \mathrm{pH} \mathrm{7.4,} 5 \mathrm{mM} \mathrm{KH}_{2} \mathrm{PO}_{4}, 10 \mathrm{mM} \mathrm{KCl}, 5 \mathrm{mM}$ $\mathrm{MgCl}_{2}$ and 0.2 mM ADP (Cain and Skilleter, 1987). Protein concentration was $0.5 \mathrm{mg} / \mathrm{ml}$ assay medium.

\subsection{Enzyme activity assays}

NADH and succinate dehydrogenase activities were studied on submitochondrial particles, to avoid permeability problems associated with the use of intact mitochondria. Enzyme activities, modified from methods described previously by other authors (Cénas et al., 1991; Liu et al., 1991), were spectrophotometrically monitored using a Shimadzu UV160A split-beam spectrophotometer, at $30^{\circ} \mathrm{C}$ in $10 \mathrm{mM}$ Tris- $\mathrm{HCl} \mathrm{pH} \mathrm{7.4,} \mathrm{and} \mathrm{with} \mathrm{a} \mathrm{protein} \mathrm{concentration} \mathrm{of}$ $0.05 \mathrm{mg} / \mathrm{ml}$. For NADH dehydrogenase the reaction was started by the addition of $0.1 \mathrm{mM} \mathrm{NADH}$ and the decrease in absorbance at $340 \mathrm{~nm}$ was registered. The basal rate of oxidation of NADH during the time of the
103 

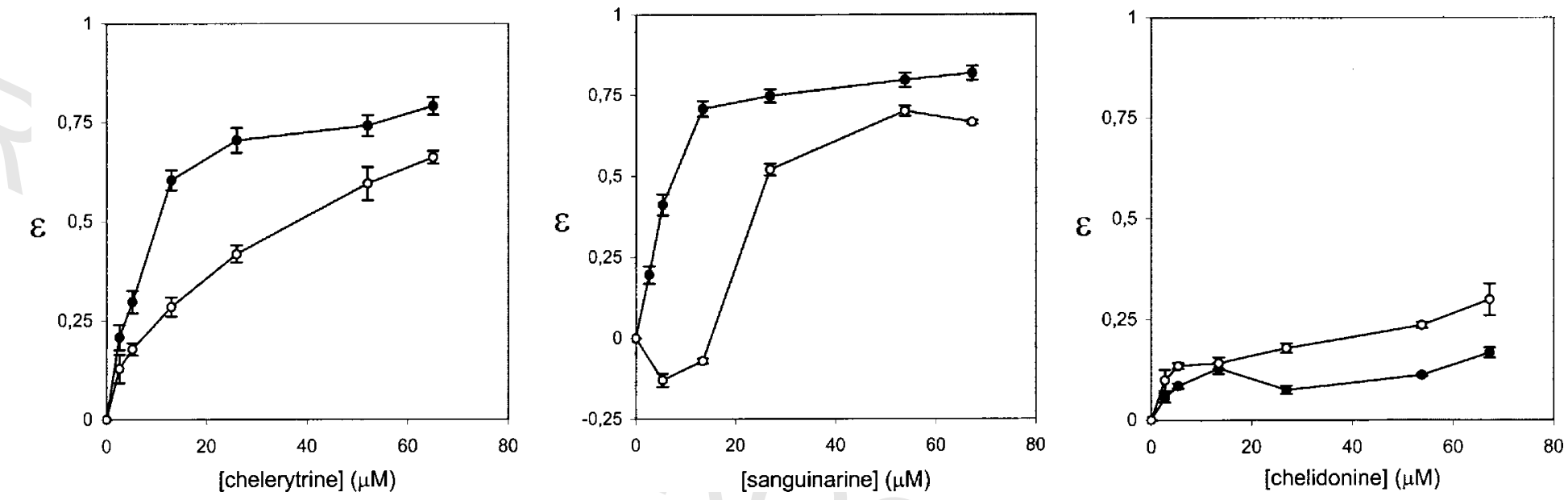

Fig. 2. Inhibition fractions $(\varepsilon)$ of oxygen uptake by intact mitochondria in the presence of group (i.a) and (i.b) alkaloids. $(\bigcirc)$ Malate + glutamate $(M+G),(\mathbf{O})$ succinate (SUC) as substrates. Oxygen uptake was followed in a Clark-type electrode. Concentration of mitochondria was $0.5 \mathrm{mg}$ protein/ml of assay medium. Results are presented as mean \pm S.D. (control values: chelerythrine, $\mathrm{M}+\mathrm{G} 16.6 \pm 1.9 \mathrm{nmol} \mathrm{O}_{2} / \mathrm{min} \mathrm{mg}$, SUC $33.3 \pm 2.6$; sanguinarine, $\mathrm{M}+\mathrm{G} 17.4 \pm 2.3$, SUC $27.5 \pm 2.6$; chelidonine, $\mathrm{M}+\mathrm{G}$ $15.5 \pm 2.0$, SUC $32.2 \pm 3.6$ ) 
assay period was negligible. The medium for succinate dehydrogenase contained $0.001 \%$ dichlorophenolindophenol; the reaction was started by the addition of $10 \mathrm{mM}$ succinate and the decrease in absorbance at $600 \mathrm{~nm}$ was followed.

\subsection{Treatment and presentation of results}

Results (media of at least three independent experiments) are presented as relative inhibitions or inhibition degrees $(\varepsilon)$, to minimize variability between different mitochondrial extractions. $\varepsilon$ was calculated as $\left(v-v_{i}\right) / v ; v$ is defined as the rate of oxygen uptake or the rate of absorbance decrease at 340 or $600 \mathrm{~nm}$, in the absence of inhibitor and $v_{i}$ the oxygen uptake or enzyme activity in the presence of an $i$ concentration of inhibitor.

\section{Results}

\subsection{Oxygen uptake by intact mitochondria}

The effects of the several groups of alkaloids on oxygen uptake in mitochondria showed different patterns. Chelerythrine and sanguinarine, both contain-

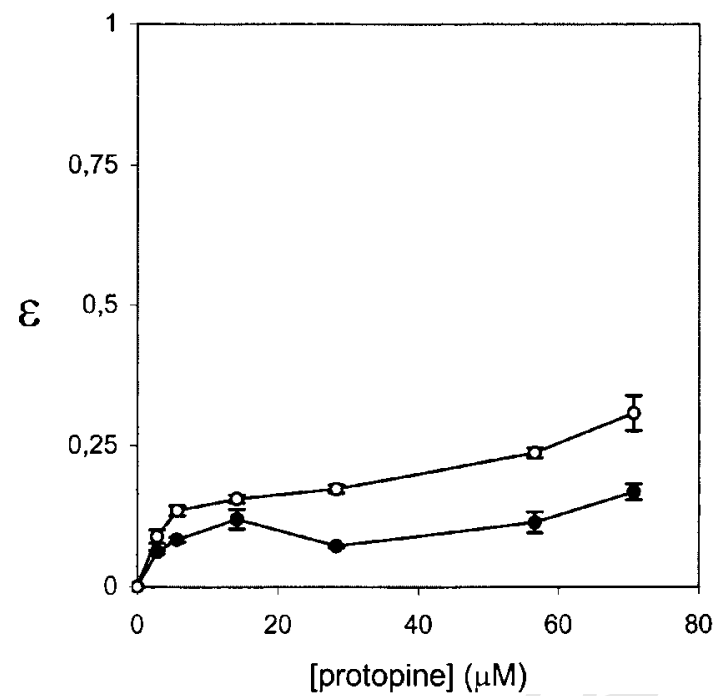

ing a quaternary nitrogen atom with a methyl group, 147 strongly inhibited succinate-dependent respiration 148 and, to a lesser extent, malate-glutamate respira- 149 tion, while chelidonine, an uncharged phenanthridine 150 derivative, had virtually no effect (Fig. 2). Protopine 151 and allocryptopine, both uncharged and with a $\mathrm{C}=\mathrm{O} \quad 152$ group, also had no apparent effect (Fig. 3). Berberine 153 and coptisine, both with an unsubstituted quaternary 154 nitrogen atom, had a marked inhibitory effect on 155 malate-glutamate respiration and a smaller, although 156 significant, effect on succinate respiration (Fig. 4). 157 Chelerythrine and berberine, which contain a quater- 158 nary nitrogen atom and methoxy substituents, showed 159 a stronger inhibitory effect of malate + glutamate 160 respiration at low concentrations, when compared, 161 with sanguinarine and coptisine, respectively (Figs. 2162 and 4). Phenanthrene had a very low effect on oxygen 163 uptake (Fig. 5).

\subsection{Enzyme activities in submitochondrial particles}

In submitochondrial particles, chelerythrine and sanguinarine inhibited succinate dehydrogenase activity to a greater extent than NADH dehydrogenase (Fig. 6). This is a type of pattern similar to the one found on oxygen uptake (Fig. 2). Therefore, the ef-

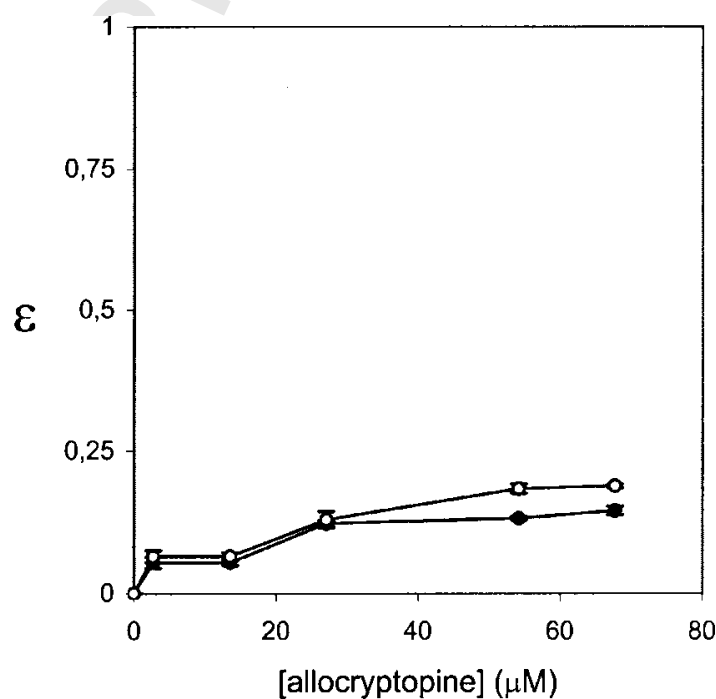

Fig. 3. Inhibition fractions $(\varepsilon)$ of oxygen uptake by intact mitochondria in the presence of group (ii) alkaloids. $(\bigcirc)$ Malate + glutamate $(\mathrm{M}+\mathrm{G}),(\mathbf{O})$ succinate (SUC), as substrates. Assay conditions were as described above. Results are presented as mean \pm S.D. (control values: protopine, $\mathrm{M}+\mathrm{G} 14.4 \pm 0.7 \mathrm{nmol} \mathrm{O} 2 / \mathrm{min} \mathrm{mg}$, SUC $26.4 \pm 2.2$; allocryptopine, $\mathrm{M}+\mathrm{G} 15.2 \pm 2.0$, SUC 27.9 \pm 1.6 ). 

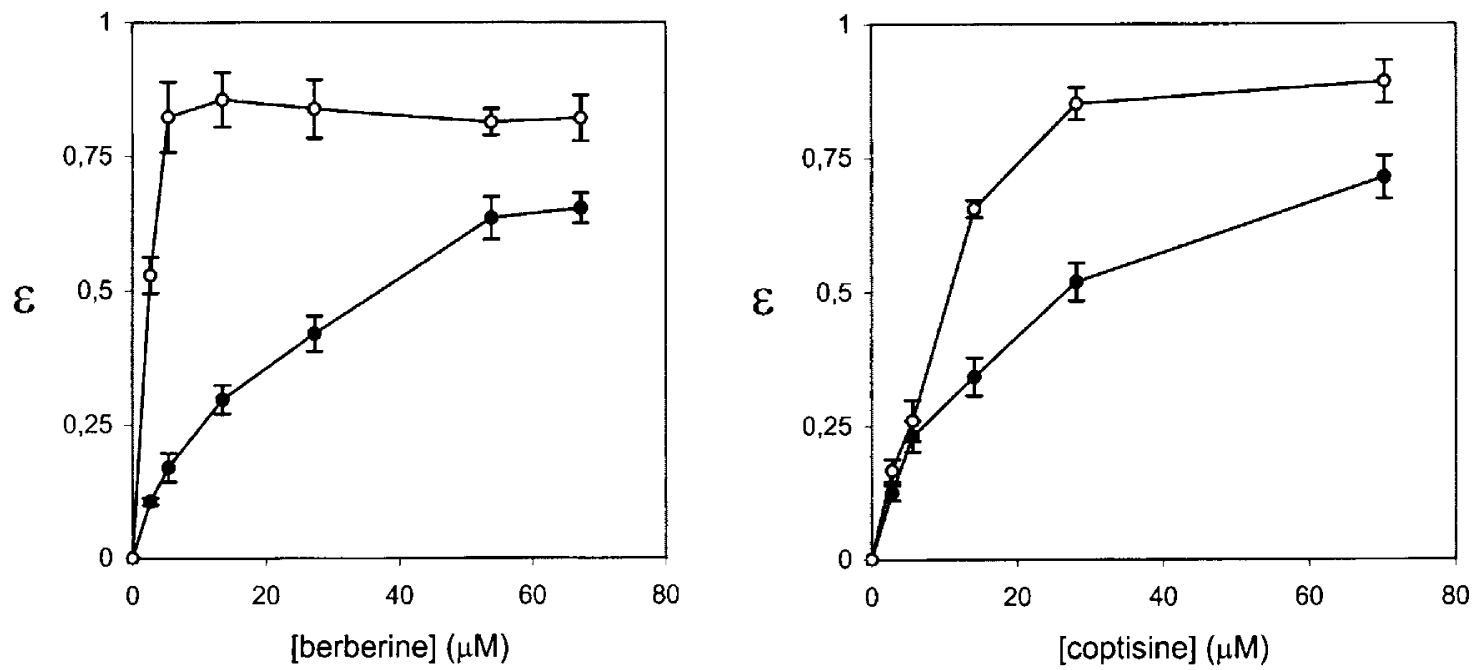

Fig. 4. Inhibition fractions $(\varepsilon)$ of oxygen uptake by intact mitochondria in the presence of group (iii) alkaloids. ( $\bigcirc$ ) Malate + glutamate $(\mathrm{M}+\mathrm{G}),(\mathrm{O})$ succinate $(\mathrm{SUC})$ as substrates. Assay conditions were as described above. Results are presented as mean \pm S.D. (control values: berberine, $\mathrm{M}+\mathrm{G} 17.5 \pm 1.9 \mathrm{nmol} \mathrm{O} / \mathrm{min} \mathrm{mg}$, SUC $27.5 \pm 4.2$; coptisine, $\mathrm{M}+\mathrm{G} 14.7 \pm 1.7$, SUC 28.5 \pm 3.5 ).

fect on mitochondrial respiration is essentially in the agreement with the effect on the two enzymes. Chelidonine caused a slight decrease on NADH dehydrogenase but not on succinate dehydrogenase

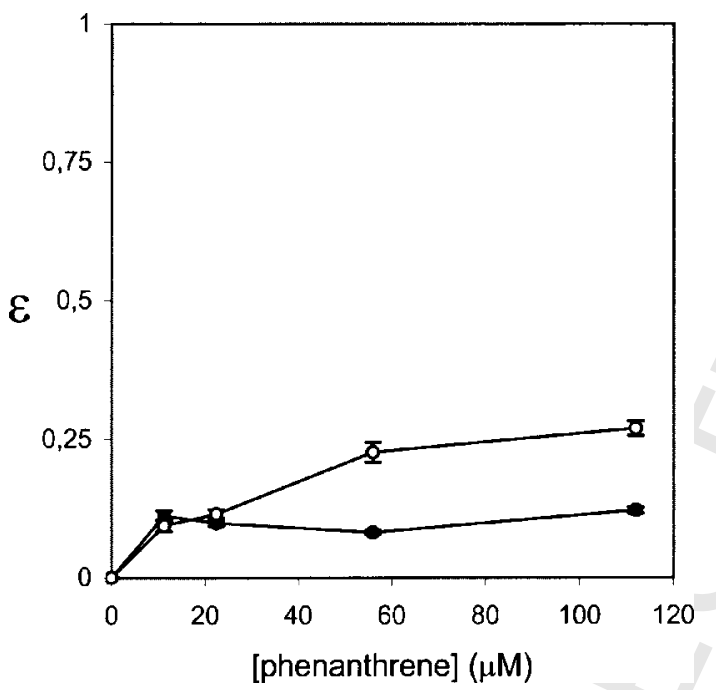

Fig. 5. Inhibition fractions $(\varepsilon)$ of oxygen uptake by intact mitochondria in the presence of phenanthrene. $(\bigcirc)$ Malate + glutamate $(M$ $+\mathrm{G})$, (O) succinate (SUC) as substrates. Assay conditions were as described above. Results are presented as mean \pm S.D. (control values: $\mathrm{M}+\mathrm{G} 15.7 \pm 1.9 \mathrm{nmol} \mathrm{O}_{2} / \mathrm{min} \mathrm{mg}$, SUC $27.8 \pm 1.6$ ). activity (Fig. 6). Protopine and allocryptopine had a 175 very strong inhibitory effect on NADH dehydroge- 176 nase activity and did not affect succinate dehydroge- 177 nase (Fig. 7). Berberine and coptisine did not inhibit 178 NADH dehydrogenase so strongly as would be ex- 179 pected by their effect on oxygen uptake, and had no 180 effect on succinate dehydrogenase (Fig. 8). Phenan- 181 threne, although it did not affect oxygen uptake to a 182 great extent, had a marked inhibitory effect on NADH 183 dehydrogenase in submitochondrial particles but not 184 on succinate dehydrogenase (Fig. 9).

\section{Discussion}

The alkaloids with a charge due to a quaternary ni- $\quad 187$ trogen atom presented a high inhibitory activity on 188 oxygen uptake (Figs. 2 and 4). Some authors have al- 189 ready observed that alkaloids containing a quaternary 190 nitrogen atom are the ones with the highest biological 191 activity (Ulrichová et al., 1984; Dostál and Potácek, 192 1990; McNaught et al., 1995, 1996).

The alkaloids which contain a methyl group linked 194 to the quaternary nitrogen atom seemed to have a 195 more significant effect on succinate-dependent pro- 196 cesses (Figs. 2 and 6). Berberine and coptisine had 197 practically no effect on succinate dehydrogenase 198 

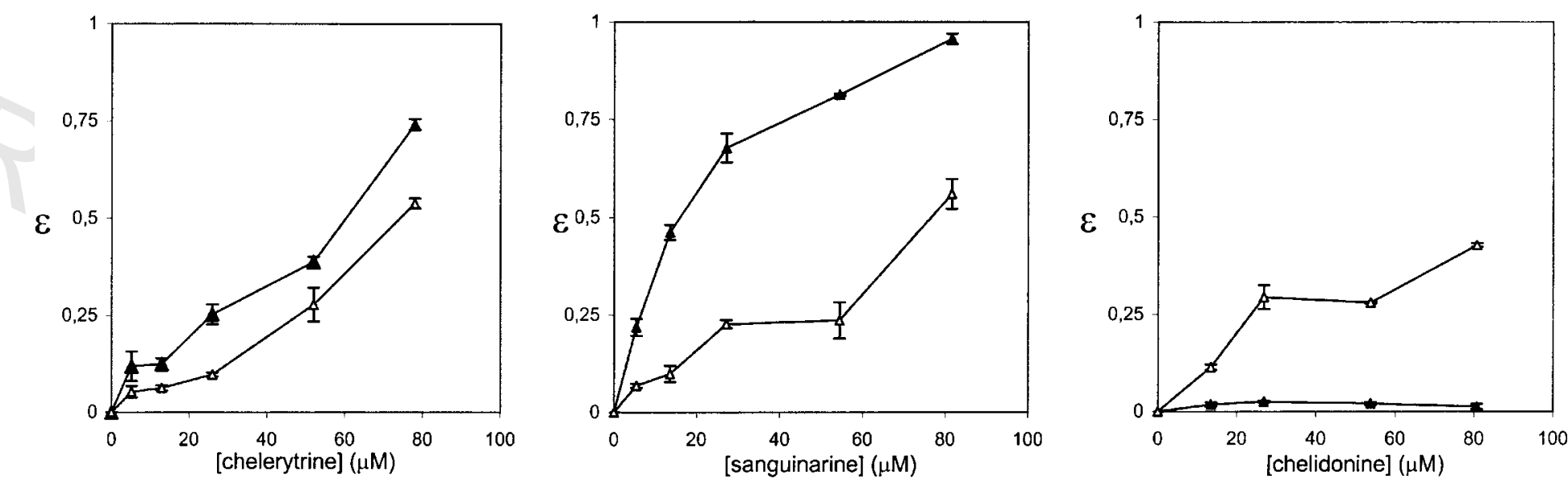

Fig. 6. Inhibition fractions $(\varepsilon)$ of NADH dehydrogenase, NADH DH $(\triangle)$ and succinate dehydrogenase, SDH $(\mathbf{\Lambda})$, in the presence of group (i) alkaloids. Enzyme activitie were spectrophotometrically monitored at $340 \mathrm{~nm}(\mathrm{NADH} \mathrm{DH})$ and at $600 \mathrm{~nm}(\mathrm{SDH})$. Concentration of SMPs was $0.05 \mathrm{mg}$ protein/ml of assay medium. Results are presented as mean \pm S.D. (control values: chelerythrine, NADH DH $0.317 \pm 0.014 \mu \mathrm{mol} \mathrm{NADH} / \mathrm{min} \mathrm{mg,} \mathrm{SDH} 0.075 \pm 0.002 \mu \mathrm{mol}$ succinate/min mg; sanguinarine, NADH DH $0.235 \pm 0.016$, SDH $0.073 \pm 0.002$; chelidonine, NADH DH $0.352 \pm 0.001$, SDH $0.095 \pm 0.001$ ). 

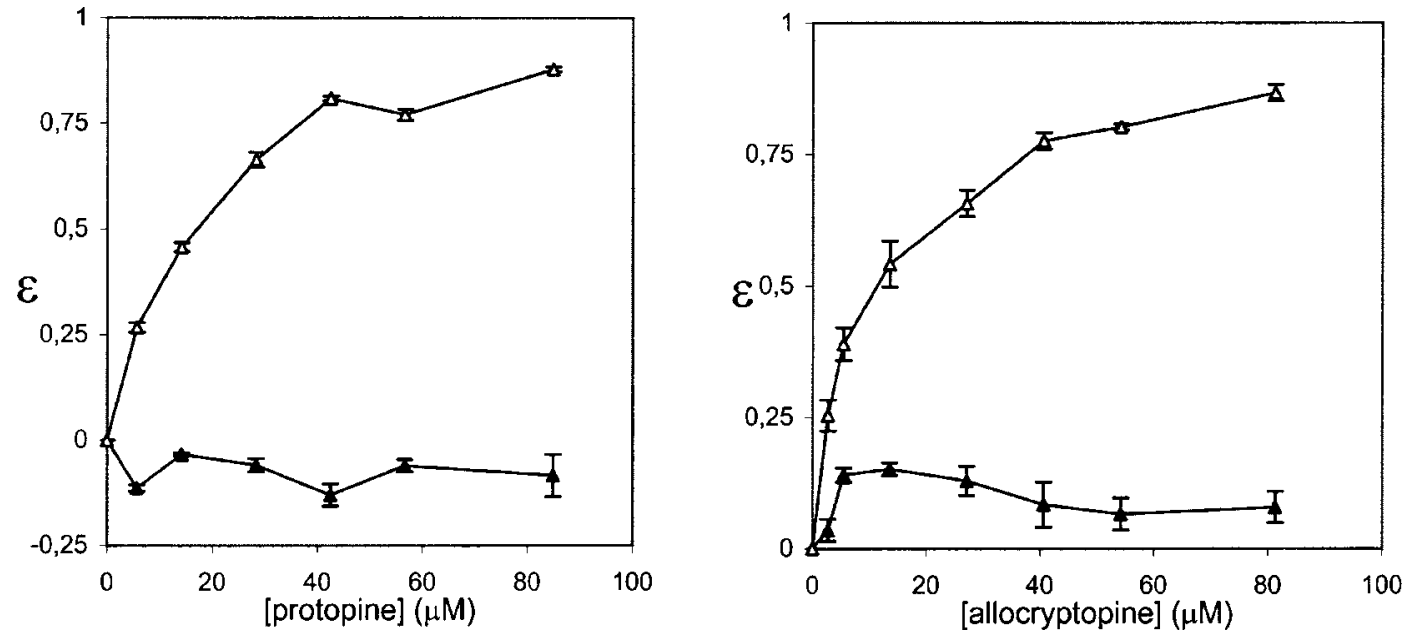

Fig. 7. Inhibition fractions $(\varepsilon)$ of NADH dehydrogenase, NADH DH $(\Delta)$ and succinate dehydrogenase, SDH $(\boldsymbol{\Delta})$, in the presence of group (ii) alkaloids. Assay conditions were as described above. Results are presented as mean \pm S.D. (control values: protopine, NADH DH $0.293 \pm 0.018 \mu \mathrm{mol} \mathrm{NADH} / \mathrm{min} \mathrm{mg}$, SDH $0.071 \pm 0.005 \mu \mathrm{mol}$ succinate/min mg; allocryptopine, NADH DH $0.286 \pm 0.023, \mathrm{SDH}$ $0.074 \pm 0.005)$

activity, although the inhibition of succinate-dependent oxygen uptake was quite marked. The pattern we observed in submitochondrial particles agreed with the results reported in another study (Schewe and Müller, 1976), which reports the effect of berberine on NADH oxidase and succinate-cytochrome $c$ oxidoreductase

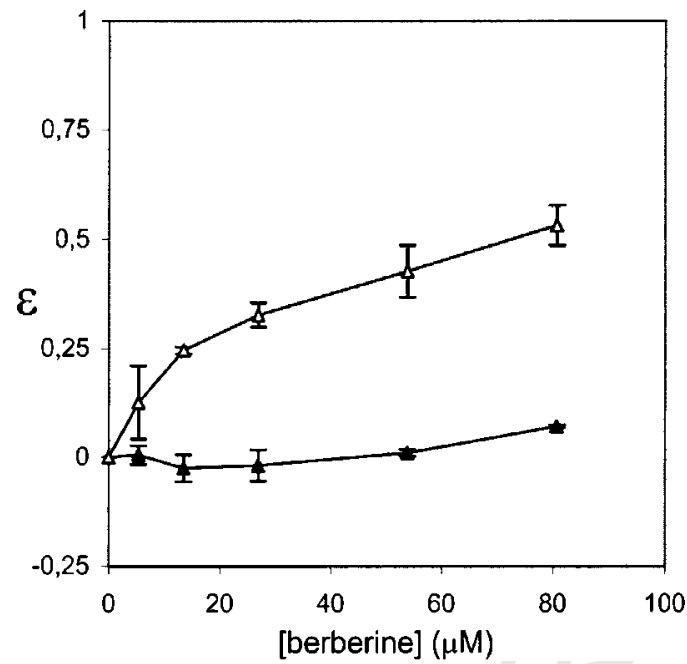

in beef heart submitochondrial particles. The authors found that berberine had a strong inhibitory effect on NADH oxidase and a much lower effect on succinate dehydrogenase activity.

In the present work, the effects of the group i and ii alkaloids tested on NADH dehydrogenase were very

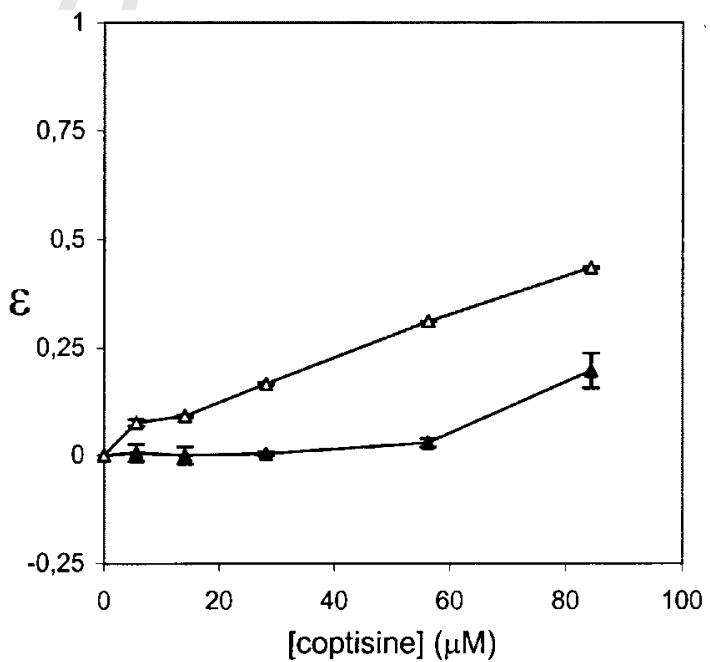

Fig. 8. Inhibition fractions $(\varepsilon)$ of NADH dehydrogenase, NADH DH $(\triangle)$ and succinate dehydrogenase, SDH $(\mathbf{\Delta})$, in the presence of group (iii) alkaloids. Assay conditions were as described above. Results are presented as mean \pm S.D. (control values: berberine, NADH DH $0.338 \pm 0.016 \mu \mathrm{mol} \mathrm{NADH} / \mathrm{min} \mathrm{mg}$, SDH $0.116 \pm 0.004 \mu \mathrm{mol}$ succinate/min mg; coptisine, NADH DH 0.337 \pm 0.009 , SDH $0.087 \pm 0.002$ ). 


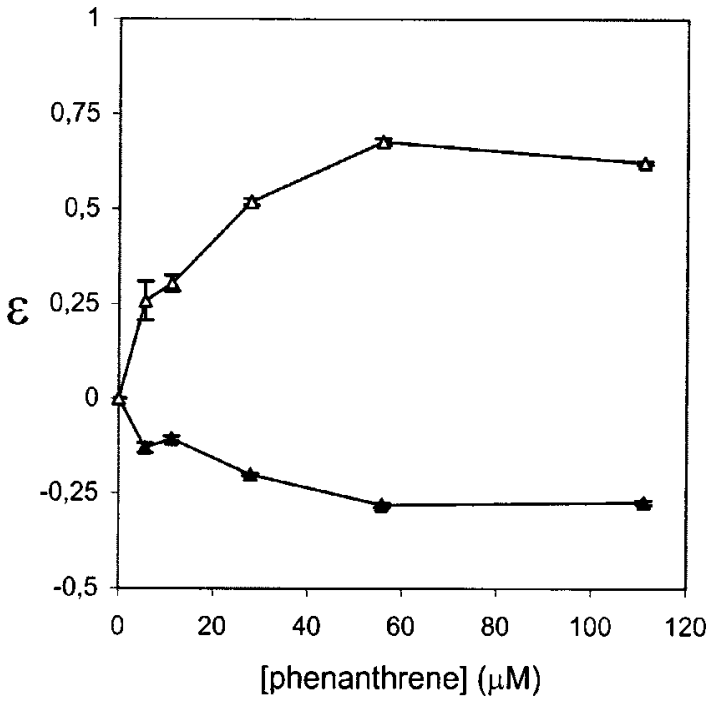

Fig. 9. Inhibition fractions $(\varepsilon)$ of NADH dehydrogenase, NADH $\mathrm{DH}(\triangle)$ and succinate dehydrogenase, $\operatorname{SDH}(\boldsymbol{\Delta})$, in the presence of phenanthrene. Assay conditions were as described above. Results are presented as mean \pm S.D. (control values: NADH DH $0.286 \pm 0.024 \mu \mathrm{mol} \mathrm{NADH} / \mathrm{min} \mathrm{mg}$, SDH $0.075 \pm 0.003 \mu \mathrm{mol}$ succinate/min $\mathrm{mg}$ ). similar. The fact that chelidonine, protopine and allocryptopine, bearing no charge, inhibited NADH dehydrogenase but had practically no effect in intact mitochondria, may have been due to the abolition of permeability barriers, since NADH dehydrogenase faces the inner side of the membrane in intact mitochondria and the outer side in submitochondrial particles (Harmon et al., 1974).

The comparative analysis between the results of respiration and of enzyme activities suggests that the uncharged compounds we tested had more difficulty in passing across the mitochondrial membrane to gain access to the enzyme molecules. The analysis of results reported by another research group (McNaught et al., 1995, 1996) corroborate this hypothesis. These authors reported that isoquinolinium cations were more active inhibitors of respiration in intact mitochondria than isoquinolines. In mitochondrial fragments, the presence of a quaternary atom was not essential for the inhibition of complex I activity (McNaught et al., 1995, 1996). This is probably correct since we found that protopine and allocryptopine produced a marked effect on NADH dehydrogenase. The differences found between mitochondria and mitochondrial fragments may be explained by a preferential transport and ac- 234 cumulation of the cations as opposed to the uncharged 235 isoquinoline molecules. The high membrane poten- 236 tial in mitochondria may result in a selective attrac- 237 tion of lipophilic cations, leading to their accumula- 238 tion on the matrix side (Ramsay and Singer, 1986; 239 Ramsay et al., 1987; Murphy, 1997). The concentra- 240 tion of positively charged alkaloids in intact mitochon- 241 dria may therefore be much higher than the concen- 242 tration of the other substances tested in the present 243 work.

The presence of a quaternary atom is not enough 245 to confer inhibitory activity to molecules, since am- 246 monium acetate, tetramethylammonium iodide and 247 tetrapropylammonium iodide had no effect on en- 248 zyme activity (results not shown). Phenanthrene, with 249 a full aromatic structure and no substituents, caused 250 a decrease on NADH dehydrogenase activity (Fig. 9). 251 NADH dehydrogenase inhibition may be associated 252 with the presence of at least two adjacent aromatic 253 rings, which are present in berberine, coptisine, chel- 254 erythrine and sanguinarine structures (Figs. 6 and 8). 255 Inhibition by protopine and allocryptopine is likely 256 due to the carbonyl group, which may react with 257 catalytically important SH groups in the enzyme 258 molecule or perhaps with the iron-sulfur clusters of 259 complex I.

The presence of four consecutive aromatic groups 261 and a positive charge, which exist in chelerythrine and 262 sanguinarine, may be a structure associated with the 263 inhibition of succinate dehydrogenase. The positive 264 charge is probably necessary, since phenanthrene, with 265 the same aromatic rings but with no charge, did not 266 inhibit this enzyme. Many observed biological effects 267 of these two alkaloids involve the formation of a labile 268 covalent bond between SH groups of cell components 269 and the electrophilic $\mathrm{C}_{6}$ carbon (Sedo et al., 2002). The 270 imminium bond in sanguinarine and chelerythrine is 271 susceptible to a nucleophilic attack and consequently 272 plays a key role in the inhibition of SH proteins. The 273 fact that hepatocytes incubated with these two alka- 274 loids suffered a dose-dependent GSH depletion cor- 275 roborates the idea that they bind to this SH peptide 276 (Ulrichová et al., 2001).

The presence of methoxy groups also contributes 278 to the difference in the inhibition strength of malate- 279 glutamate-dependent oxygen uptake at low alkaloid 280 concentrations between the positively charged alka- 281 
loids which contain methoxy groups and those where they are absent (chelerythrine versus sanguinarine and berberine versus coptisine, Figs. 2 and 4). This may be due to an easier passage of these alkaloids across the membrane and/or to an increased inhibition of NADH dehydrogenase, in the case of berberine.

Berberine, containing both a quaternary nitrogen atom and methoxy groups, was the most biologically active of all the alkaloids tested, and therefore it should have the highest toxicity.

We suggest that the biological effects of the alkaloids on mitochondria are due to (i) the positive charge of the alkaloids, which causes their accumulation inside the organelle and (ii) inhibition of both NADH and/or succinate dehydrogenase activity and probably also inhibition at the cytochrome level, since in some cases the effects on respiration are not fully explained by the effects on the enzymes. This is corroborated by preliminary results from our laboratory (unpublished data) which show that berberine inhibits cytochrome $\mathrm{aa}_{3}$ reduction.

\section{Acknowledgements}

We would like to thank Professor Slavik (Purkine University, Brno, Czech Republic) for the kind gift of alkaloids from Chelidonium majus.

\section{References}

Bézanger-Beauquesne, L., Pinkas, M., Torck, M., Trotin, F., 1990. Plantes médicinales des régions tempérées, second ed. Ed. Maloine, Paris.

Bradford, M.M., 1976. A rapid, sensitive method for the determination of protein concentrations using the Coomassie dyebinding. Anal. Biochem. 72, 248-254.

Cain, K., Skilleter, D.N., 1987. Preparation and use of mitochondria in toxicological research. In: Snell, K., Mullock, B. (Eds.), Toxicology: A Molecular Approach. IRL Press, pp. 217253.

Cénas, N.K., Bironaité, D.A., Kulys, J.J., 1991. On the mechanism of rotenone-insensitive reduction of quinones by mitochondrial NADH: ubiquinone reductase. The high affinity binding of $\mathrm{NAD}^{+}$and $\mathrm{NADH}$ to the reduced enzyme form. FEBS Lett. 284, 192-194.

Colombo, M.L., Bosisio, E., 1996. Pharmacological activities of Chelidonium majus L. (Papaveraceae). Pharmacol. Res. 33, 127-134.
Dostál, J., Potácek, M., 1990. Quaternary benzo[c]phenanthridine 327 alkaloids. Collect. Czech. Chem. Commun. 55, 2840-2871.

Duke, J., 1985. Handbook of Medicinal Herbs. CRC Press, London. 329

Harmon, H.J., Hall, J.D., Crane, F.L., 1974. Structure of mito- 330 chondrial cristae membranes. Biochim. Biophys. Acta 344, 331 119-155.

Kadan, G., Gözler, T., Shamma, M., 1990. (-)-Turkiyenine, a new 333 alkaloid from Chelidonium majus. J. Nat. Prod. 53, 531-532. 334

Lavenir, R., Paris, R.R., 1965. Sur les alcaloïdes de la chélidoine 335 (Chelidonium majus L.): repartition dans divers organes, 336 isolement de la stylopine a partir des fruits. Ann. Pharmaceut. 337 Françaises 23, 307-312.

Liu, C., Xu, J.X., Gu, L.Q., 1991. Inhibition of succinate- 339 ubiquinone reductase by nitrosalicyl- $N$-alkylamides. Biochim. 340 Biophys. Acta 1057, 373-376.

McNaught, K.St.P., Thull, U., Carrupt, P.A., Altomare, C., 342 Cellamare, S., Carotti, A., Testa, B., Jenner, P., Marsden, 343 C.D., 1995. Inhibition of complex I by isoquinoline derivatives 344 structurally related to 1-methyl-4-phenyl-1,2,3,6-tetrahydro- 345 pyridine (MPTP). Biochem. Pharmacol. 50, 1903-1911. 346

McNaught, K.St.P., Thull, U., Carrupt, P.A., Altomare, C., 347 Cellamare, S., Carotti, A., Testa, B., Jenner, P., Marsden, C.D., 348 1996. Effects of isoquinoline derivatives structurally related 349 to 1-methyl-4-phenyl-1,2,3,6-tetrahydropyridine (MPTP) on 350 mitochondrial respiration. Biochem. Pharmacol. 51, 1503- 351 1511.

Murphy, M.P., 1997. Selective targeting of bioactive compounds 353 to mitochondria. Tibtech. 15, 326-330.

Paris, R.R., Moyse, H., 1967. Précis de matière médicale, vol. II. 355 Masson Ed., Paris, pp. 207-208. 356

Pavão, M.L., Pinto, R.E., 1995. Densitometric assays for the 357 evaluation of water soluble alkaloids from Chelidonium majus 358 L. (Papaveraceae) roots in the Azores, along one year cycle. 359 Arquipélago, Sér. Ciências Biol. Marinhas 13, 89-91. 360

Ramsay, R.R., Singer, T.P., 1986. Energy-dependent uptake 361 of $N$-methyl-4-phenylpyridinium, the neurotoxic metabolite 362 of 1-methyl-4-phenyl-1,2,3,6-tetrahydropyridine, by mitochon- 363 dria. J. Biol. Chem. 261, 7585-7587. 364

Ramsay, R.R., Kowal, A.T., Johnson, M.K., Salach, J.I., Singer, 365 T.P., 1987. The inhibition site of MPP+, the neurotoxic bioacti- 366 vation product of 1-methyl-4-phenyl-1,2,3,5-tetrahydropyridine 367 is near the Q-binding site of NADH dehydrogenase. Arch. 368 Biochem. Biophys. 259, 645-649.

Schewe, T, Müller, W, 1976. Hemmung der Atmungskette 370 durch die Alkaloïde Berberinsulfat, Alpinigenin und Tetrahy- 371 dropalmatin. Acta Biol. Med. Ger. 35, 1019-1021. 372

Sedo, A., Vlasicová, K., Barták, P., Vespalec, R., Vicar, J., 373 Simánek, V., Ulrichová, J., 2002. Quaternary benzo[c]phenan- 374 thridine alkaloids as inhibitors of aminopetidase $N$ and 375 dipeptidyl peptidase IV. Phytother. Res. 16, 84-87. 376

Táborská, E., Bochoráková, H., Paulová, H., Dostál, J., 1994. 377 Separation of alkaloids in Chelidonium majus by reversed phase 378 HPLC. Planta Med. 60, 380-381.

Tomé, F., Colombo, M.L., 1995. Alkaloids from Chelidonium 380 majus: distribution in the plant and factors affecting their 381 accumulation. Phytochemistry 40, 3-39. 
Ulrichová, J., Walterová, D., Simánek, V., 1984. Molecular mechanisms of the biological activity of quaternary benzophenanthridine and protoberberine alkaloids. Acta Univ. Palack. Olomuc. Fac. Med. 106, 31-38.

Ulrichová, J., Dvorák, Z., Vicar, J., Lata, J., Smrzová, J., Sedo, A., Sománek, V., 2001. Cytotoxicity of natural compounds in hepatocyte cell culture models. The case of quaternary 387 benzo $[c]$ phenanthridine alkaloids. Toxicol. Lett. $125,125-388$ 132.

Vallejos, R.H., Rizzotto, M.G., 1972. Effect of chelerythrine on 390

mitochondrial energy coupling. FEBS Lett. 21, 195-198. 391 Xème Pharmacopée Française, 1989. 